\title{
Inpatient subacute care in Australia: perceptions of admission and discharge barriers
}

\section{Peter W New MB BS, MClinEpi, FAFRM(RACP) Head of Rehabilitation; PhD Candidate; Principal Researcher \\ Peter A Cameron MB BS, MD, FACEM Director, Centre of Research Excellence in Patient Safety ${ }^{2}$ \\ John H Olver MB BS, MD, FAFRM (RACP) Director, Rehabilitation \\ Johannes U Stoelwinde MB BS, MD, FRACMA, Chair, Health Services Management \\ 1 Rehabilitation and Aged Care Services, Medical Program, Southern Health Melbourne, VIC \\ 2 Department of Epidemiology and Preventive Medicine Monash University, Melbourne, VIC. \\ 3 Epworth HealthCare \\ Monash University, \\ Melbourne, VIC. \\ Peter.New@ Southernhealth.org.au}

MJA 2011; 195: 538-541: doi: 10.5694/mjal0.11361
T here is increasing concern in Australia about the long waiting times for patients attending emergency departments or requiring elective surgery. ${ }^{1,2}$ The National Hospital and Health Reform Commission has recommended a substantial increase in the number of inpatient beds for subacute care (eg, rehabilitation medicine and aged care), to meet projected demands. ${ }^{3}$ However, if, as in other sectors of the health service, there are problems with barriers to admission to subacute care or discharge from subacute care, it may be more efficient to divert some of this funding for extra beds into programs to overcome these barriers.

Few studies have focused on patient flow in the subacute sector. Difficulties for patients accessing subacute care have been identified in one acute care hospital, ${ }^{4}$ and barriers to discharge from subacute care have been explored in a viewpoint article. ${ }^{5}$ However, it is not known to what extent access or discharge problems occur more generally, or whether they differ across the various components of subacute care. Are there differences between the public and private sectors, or between the rehabilitation and aged care streams? Do hospital executives or those in senior management with responsibility for patient flow share the views of clinicians on access and discharge problems? Answering these questions is important for developing a shared vision for system improvements.

As little is known about the problems of subacute patient flow, a survey was designed to determine the perceptions of key stakeholders in subacute care. Opinions were sought from: (i) specialist doctors working in subacute inpatient units; and (ii) senior hospital managers with responsibility for patient flow in subacute care.

\section{Methods}

\section{Survey development}

The survey was developed by one of us (PWN) based on clinical experience

\section{Abstract}

Objective: To determine perceptions of barriers to admission to subacute care from acute hospital care, and barriers to subsequent discharge from subacute care.

Design, participants and setting: Web-based survey of key stakeholders using Likert scales and closed questions. Prompts were emailed repeatedly to potential participants in Australia between 15 May and 24 July 2009.

Participants were physicians working in inpatient rehabilitation medicine and aged care units, as well as senior hospital managers with responsibility for patient flow.

Main outcome measures: Perceived admission and discharge barriers in subacute care.

Results: Half of the 101 respondents reported barriers to admission to subacute hospitals as moderate, severe or extreme, and $81 \%$ reported a similar grading of severity for barriers to discharge. There was no relationship between these perceptions and whether respondents worked only in the public hospital system (barriers to access: $\chi^{2}=0.02[\mathrm{df}=1 ; P=1.0]$; and barriers to discharge: $\chi^{2}=0.0$ $[\mathrm{df}=1 ; P=1.0]$ ). The most commonly reported barriers to admission were: availability of beds ( $61 \%$ of respondents); physical, environmental and equipment inadequacies (62\% of respondents); and allied health or nursing staff issues ( $55 \%$ of respondents). The most commonly reported barriers to discharge included: waiting for a more appropriate setting of care (76\% of respondents) and funding for home modifications, equipment or carers (55\% of respondents). There was no relationship between respondents' position and their reporting of various admission $\left(\chi^{2}=6.2 ; \mathrm{df}=8 ; P=0.6\right)$ or discharge barriers $\left(\chi^{2}=13.8 ; \mathrm{df}=12 ; P=0.3\right)$.

Conclusion: There is a strong perception among key stakeholders in subacute care that there are major barriers to patient admission and discharge.

Redistributing proposed funding for inpatient subacute beds to measures for overcoming these barriers is likely to improve patient flow though the whole hospital system.

and a literature review. Principles of good survey design were followed in developing and distributing the survey. ${ }^{6}$ A web-based survey (SurveyMonkey, Palo Alto, Calif, USA) was piloted and refined to optimise the clarity, readability and focus of the questions, and to achieve a target completion time of about 10 minutes. The survey period commenced on 15 May 2009 and concluded on 24 July 2009.

Respondents were asked about their position and training, as well as their demographic characteristics. Their views about admission and discharge barriers for inpatients needing subacute care were canvassed using Likert scales and closed questions (limited choice, multiple choice, and checklists), as well as a few open questions allowing free-text answers (a copy of the survey is available from $\mathrm{PWN}$ ).

\section{Survey participants and recruitment}

The survey targeted physicians working in rehabilitation medicine and in aged care; and senior hospital management personnel with responsibility for patient flow from acute care to inpatient subacute care and from inpatient subacute care to the community.

Although palliative care and psychiatry are also components of subacute care, ${ }^{7}$ physicians in these areas were not included as their patientflow issues are somewhat different. Also excluded were physicians working in paediatric rehabilitation medicine, and psychogeriatric and dementia units. Finally, physicians not working in inpatient units were also excluded from the survey.

The professional organisations representing rehabilitation medicine (Australasian Faculty of Rehabilitation Medicine) and aged care (Australian and New Zealand Society of Geriatric Medicine) were contacted for information about how many of their members would be eligible to complete the survey. Unfortunately, nei- 
1 Characteristics of respondents and perceptions of problems of access to subacute care and barriers to discharge from subacute care

\begin{tabular}{|c|c|c|c|c|}
\hline & $\begin{array}{l}\text { Aged care } \\
\text { physicians }\end{array}$ & $\begin{array}{l}\text { Rehabilitation } \\
\text { physicians }\end{array}$ & $\begin{array}{l}\text { Hospital } \\
\text { managers }\end{array}$ & $P$ \\
\hline No. (\%), response rate & $\begin{array}{l}41(41 \%) \\
\quad 43 \%\end{array}$ & $\begin{array}{c}39 \\
(39 \%), 24 \%\end{array}$ & $\begin{array}{l}21(21 \%), \\
\text { unknown }\end{array}$ & \\
\hline $\begin{array}{l}\text { Years since Fellowship, or in } \\
\text { management position, median } \\
\text { (IQR) }\end{array}$ & $\begin{array}{c}9 \\
(2-19)\end{array}$ & $\begin{array}{c}9 \\
(4-15)\end{array}$ & $\begin{array}{c}10 \\
(5-15)\end{array}$ & $\begin{array}{c}\text { Kruskal-Wallis } \\
\begin{array}{c}H=0.3 \\
P=0.9\end{array}\end{array}$ \\
\hline $\begin{array}{l}\text { No. of inpatient beds } \\
\text { responsible for, median } \\
\text { (IQR) }\end{array}$ & $\begin{array}{c}16 \\
(12-23)\end{array}$ & $\begin{array}{c}21 \\
(15-30)\end{array}$ & $\begin{array}{c}119 \\
(42-300)\end{array}$ & $\begin{array}{c}\text { Kruskal-Wallis } \\
\quad H=24.0 ; \\
P=0.001\end{array}$ \\
\hline \multicolumn{5}{|c|}{ Problems with access to subacute inpatient beds:* } \\
\hline In your unit & & & & $\begin{array}{c}\chi^{2}=1.5 \\
\text { df }=4 ; P=0.9\end{array}$ \\
\hline Extreme & 0 & $3 \%$ & na & \\
\hline Severe & $2 \%$ & $3 \%$ & na & \\
\hline Moderate & $37 \%$ & $35 \%$ & na & \\
\hline Minor & $49 \%$ & $43 \%$ & na & \\
\hline No problem & $12 \%$ & $16 \%$ & na & \\
\hline $\begin{array}{l}\text { In your hospital } \\
\text { or organisation }\end{array}$ & & & & $\begin{array}{c}\chi^{2}=5.1 \\
\mathrm{df}=8 ; P=0.7\end{array}$ \\
\hline Extreme & $2 \%$ & $3 \%$ & $5 \%$ & \\
\hline Severe & $5 \%$ & $3 \%$ & $5 \%$ & \\
\hline Moderate & $42 \%$ & $49 \%$ & $43 \%$ & \\
\hline Minor & $44 \%$ & $31 \%$ & $38 \%$ & \\
\hline No problem & $7 \%$ & $15 \%$ & $10 \%$ & \\
\hline $\begin{array}{l}\text { In the health system } \\
\text { in general }\end{array}$ & & & & $\begin{array}{c}\chi^{2}=6.8 \\
\mathrm{df}=8 ; P=0.6\end{array}$ \\
\hline Extreme & 0 & $3 \%$ & $5 \%$ & \\
\hline Severe & $20 \%$ & $13 \%$ & $24 \%$ & \\
\hline Moderate & $68 \%$ & $67 \%$ & $67 \%$ & \\
\hline Minor & $12 \%$ & $13 \%$ & $45 \%$ & \\
\hline No problem & 0 & $5 \%$ & 0 & \\
\hline
\end{tabular}

Problems with barriers to discharge from subacute inpatient beds:*

\section{From your unit}

Extreme

Severe

Moderate

Minor

No problem

From your hospital

or organisation

Extreme

Severe

Moderate

Minor

No problem

From the health system in general

Extreme

Severe

Moderate

Minor

No problem

= $=$ terquartile range. $\mathrm{na}=$ not applicable (hospital managers not involved in individual unit access or discharge barriers. ther organisation had this information, nor were they aware of other sources of this information. However, they were able to provide an estimate based on the knowledge of senior members. Likewise, neither of the two organisations representing hospital management (Australian Healthcare and Hospitals Association, Australian Private Hospitals Association) could provide information about how many of their members were eligible to participate.

\section{Survey distribution}

An outline of the survey rationale and the URL link was repeatedly emailed (fortnightly to monthly) to potential participants by the organisations that agreed to participate in this process (those listed in the previous paragraph as well as the Royal Australasian College of Physicians). As this was an exploratory study of this topic, there was no predetermined sample size.

\section{Analysis}

Descriptive analysis was performed comparing the responses of the three participant groups regarding the extent to which barriers were perceived. We assessed (a) whether there was an influence on responses according to the number of years since specialisation (physicians working in rehabilitation medicine or aged care) or the number of years involved in patient flow (hospital management); and (b) whether the respondents worked exclusively in the public hospital system. To facilitate analysis, responses were collapsed into those reporting "extreme", "severe" or "moderate" problems, and those reporting only "minor" or "no problem".

Categorical responses were analysed using the $\chi^{2}$ test, with the Fisher exact correction used throughout because the numbers were small. Data not normally distributed (eg, number of years since completing specialist training or working in patient-flow management) were analysed using the Kruskal-Wallis H test. $P$ values of less than 0.05 were deemed statistically significant.

\section{Ethics approval}

Approval for the project was obtained from the Monash University Human 
2 Barriers to subacute care admission and discharge commonly reported by respondents*

\begin{tabular}{lc} 
Barriers to admission to subacute care & $\begin{array}{c}\text { Reported } \\
\text { by: }\end{array}$ \\
\hline Number of available beds & $61 \%$ \\
Physical/environmental issues (eg, lack of single rooms) & $59 \%$ \\
Staffing issues - allied health & $45 \%$ \\
Staffing issues - nursing staff & $39 \%$ \\
Equipment issues (eg, lack of hoists, bariatric equipment) & $32 \%$ \\
Barriers to discharge from subacute care & \\
\hline $\begin{array}{l}\text { Locating suitable accommodation } \\
\text { Patients non-weight-bearing after lower-limb fracture }\end{array}$ & $68 \%$ \\
and no longer benefiting from inpatient therapy & $63 \%$ \\
Waiting for high-level care & $63 \%$ \\
Funding for home modifications & $46 \%$ \\
Lack of suitable ambulatory therapy options & $45 \%$ \\
Funding for necessary equipment & $39 \%$ \\
Carer funding or recruitment, including support packages & $37 \%$ \\
\hline * The items above are taken directly from the survey. $†$ More than \\
one response could be given, so totals do not add up to 100\%.
\end{tabular}

Research Ethics Committee and the Southern Health Human Research Ethics Committee.

\section{Results}

One hundred and one surveys met the inclusion criteria (another 13 had substantial amounts of missing information and were excluded). The proportion of respondents from the states and territories approximated that of the Australian population. The average (SD) age of respondents was 45 (11) years (range, 28-77 years), and there was a higher proportion of female respondents $(62,61 \%)$. Sixtyeight worked in the public sector, 16 in the private sector, and 17 in both the public and private sectors.

\section{Perception of access and discharge barriers}

Respondents' perceptions of problems accessing subacute beds and being discharged from subacute care are shown in Box 1. On average, 40\% of clinicians (both rehabilitation medicine and aged care physicians) indicated that there were moderate, severe or extreme access problems for patients waiting for admission to their units, and $50 \%$ of all respondents indicated similar difficulty for their hospital as a whole.

There was no relationship between the number of years since completing specialisation and perception of unit access problems (Kruskal-Wallis $\mathrm{H}=$ 3.6; $P=0.06$ ), and neither was the response influenced by whether the participating physicians worked in the public versus the private sector or in both sectors (barriers to unit access: $\chi^{2}=1.5[\mathrm{df}=1 ; P=0.3]$; and barriers to hospital access: $\chi^{2}=0.02$ $[\mathrm{df}=1 ; P=1.0])$. However, respondents who had spent less time working in their field were significantly more likely (Kruskal-Wallis $\mathrm{H}=6.1 ; P=$ 0.01 ) to perceive a moderate or worse problem with patients' access to subacute beds for their hospital.

More respondents perceived barriers to discharge from subacute care than perceived barriers to admission, with an average of $73 \%$ of clinicians indicating that there were moderate, severe or extreme problems with discharging patients from their units, and $81 \%$ of all respondents perceived a similar grading of severity for barriers to discharging patients from the hospital in which they worked. There was no relationship between the number of years since specialisation and the perception of the severity of discharge barriers for hospital units (Kruskal-Wallis $\mathrm{H}=1.2 ; \mathrm{P}=0.3$ ); neither was there any influence on this perception according to sector setting (barriers to unit discharge: $\chi^{2}=0.2$ $[\mathrm{df}=1 ; P=0.8]$; and barriers to hospital discharge: $\chi^{2}=0.0[\mathrm{df}=1 ; P=1.0]$ ). Respondents who had spent less time working in their field were much more likely (Kruskal-Wallis $\mathrm{H}=4.2$; $P=0.04$ ) to perceive a moderate or worse problem with discharging patients from subacute beds in their hospital.

\section{Causes of access and discharge barriers}

The most commonly perceived causes of barriers to admission to and discharge from subacute beds are listed in Box 2. Overall, the most commonly perceived barriers to admitting patients to subacute care included bed availability (61\% of respondents); physical, environmental or equipment inadequacies (62\% of respondents); and allied health or nursing staffing issues (55\% of respondents). The most commonly perceived barriers to patient discharge included waiting for a more appropriate setting of care $(76 \%$ of respondents) and inadequate funding for home modifications, necessary equipment, or carers (55\% of respondents). There was no relationship between respondents' position and their reporting of various admission $\left(\chi^{2}=6.2 ; \mathrm{df}=8 ; P=0.6\right)$ or discharge barriers $\left(\chi^{2}=13.8 ; \mathrm{df}=12 ; P=0.3\right)$.

Two respondents reported that access to subacute beds was restricted by limited weekend admissions, and each of the following problems were reported by one respondent: lack of understanding of the processes involved (did not specify what processes) in acute hospitals; clinician shortage (did not specify which clinicians); inadequate numbers of rehabilitation medicine and nursing staff to triage referred patients; discharge planning issues; and poor financial reimbursement of hospitals for treating patients in the subacute sector.

Additional reasons nominated by respondents as barriers to discharge from subacute care included: delays in appointing a guardian $(n=8)$; difficulties in discharging patients aged under 65 years to high-level care $(n=$ $7)$; family negotiations around discharge planning decisions $(n=5)$; waiting for the aged care assessment service processes to be completed ( $n=$ $2)$; waiting for home modifications to be completed $(n=2)$; and waiting for low-level care beds $(n=2)$.

\section{Discussion}

All respondent groups, but especially rehabilitation physicians, reported barriers to discharge of inpatients after subacute care. Fewer respondents, but still a concerning proportion, reported barriers to admission of acute hospital patients to subacute care. The perceived severity of access problems did not vary between respondent groups, and the commonly reported causes of admission and discharge barriers were consistent across the respondent groups.

There are few studies available that can be compared with ours. One in the United Kingdom highlighted problems with neurosurgical patients unable to access rehabilitation. ${ }^{8} \mathrm{~A}$ New South Wales based study found that most acute-care hospital patients referred for rehabilitation or aged care were assessed within 2 days, and most needing admission were transferred to a subacute bed within 2 days. ${ }^{9}$ 
Another reported that most patients referred for rehabilitation no longer met formal criteria for acute care at the time of referral, indicating that they should have been referred sooner. ${ }^{4}$ Many of the barriers perceived by respondents in our study have been highlighted previously. ${ }^{5}$

It is not possible to determine why respondents who had worked for a shorter time in their field were more likely to report access or discharge barriers as moderate or worse. Reasons could include younger respondents being less likely to tolerate barriers than older colleagues. Of interest was the similarity in perception of admission or discharge barriers between respondents working in the public sector and those working in the private sector or in both sectors. For rehabilitation patients this may be partially explained by selection bias resulting in patients in the private sector tending to be less disabled. ${ }^{10}$

The finding that rehabilitation medicine physicians are much more likely to report difficulties with barriers to discharge is not surprising. Most reasons for this relate to insufficient options for care and support after discharge for severely disabled patients. These have been highlighted previously. ${ }^{5}$ The barriers to discharge also reflect the inadequate distribution and coordination of subacute services for older patients and insufficient nursing home beds. ${ }^{11}$

Improving the design and coordination of programs managed by the federal and state departments covering ageing, health, disability and social services would go a long way towards overcoming the barriers identified in our study. Unfortunately, this solution has not been included in the proposed health reforms. ${ }^{3}$ The results of our survey strongly suggest that consideration should be given to directing some of the proposed increase in funding for subacute inpatient beds ${ }^{3}$ to strategies that address subacute care admission and discharge barriers. It is quite likely that this approach would be more efficient and costeffective than providing and staffing all the proposed inpatient beds. It is also vital that the hospital networks play an active role in overcoming barriers to patient flow through the subacute sector.

Limitations of our survey include the possibility of responder bias. Moreover, it was not possible to determine the potential number of hospital management staff with responsibility for patient flow, and therefore no response rate could be determined for this group. We were only able to estimate the number of potential eligible participants from rehabilitation medicine and aged care. Nevertheless, it is believed that our results are generally reflective of the key stakeholder groups.

The implications of our study for health managers and policymakers are that they should consider patient flow inefficiencies through the whole hospital system and not focus just on the emergency department and acute hospitals. Efficiency of the health system cannot be optimised unless subacute care is better integrated into the acute hospital system. ${ }^{5}$ Research is required to measure the occurrence and causes of barriers to patient flow in subacute care, especially barriers to discharge. A prerequisite for this research should include a framework and a suite of suitable measures that could allow the barriers to be identified and targeted for improvement. In turn, this should improve the flow of patients through the entire hospital system.

Acknowledgements: For assisting in refining the pilot version of the survey, we thank Michele New; Associate Professor Christopher J Poulos, Hammond Chair of Positive Ageing and Care, University of New South Wales; Dr Richard Bignell; Associate Professor Fary Kahn,
Principal Fellow, Department of Medicine, Dentistry and Health Sciences, University of Melbourne; and Dr Hean See Tan, Acute Rehabilitation Program, Kingston Centre, Southern Health, Victoria.

We thank the participants who completed the survey and those people (and their associated institutions) who assisted with distributing information about the survey: Maggie Chen, Administrative Officer, Australasian Faculty of Rehabilitation Medicine (AFRM); Michelle Maradin, Administrative Officer, and Fairlie Clifton, Acting Senior Executive Officer, Royal Australasian College of Physicians: Robyn Baker, Administration Officer, Australian and New Zealand Society of Geriatric Medicin (ANZSGM); Prue Power, Executive Director, Australian Health Care and Hospital Association; and Dr Barbara Carney, Director Policy and Research, Australian Private Hospitals Association. Dr Jeffrey Rowland, President of the ANZSGM, and Dr Kathleen McCarthy, President of the AFRM, are thanked for providing the estimated numbers of members potentially eligible to complete the survey.

Competing interests: No relevant disclosures.

Received 21 Nov 2010, accepted 9 Jun 2011.

1 Cameron PA, Joseph AP, McCarthy SM. Access block can be managed. Med J Aust 2009; 190: 364-368.

2 Richardson D, Kelly AM, Kerr D. Prevalence of access block in Australia 2004-2008. Emerg Med Australas 2009; 21: 472-478.

3 National Health and Hospitals Reform Commission. A healthier future for all Australians: final report June 2009. http://www. nhhrc.org.au/internet/nhhrc/publishing.nsf/ Content/nhhrc-report (accessed Nov 2010).

4 Poulos CJ, Eagar K, Poulos RG. Managing the interface between acute care and rehabilitation - can utilisation review assist? Aust Health Rev 2007; 31 Suppl 1: S129-S140.

5 New PW, Poulos CJ. Functional improvement of the Australian health care system - can rehabilitation assist? Med J Aust 2008; 189 : 340-343.

6 Dillman DA. Mail and internet surveys. The tailored design method. 2nd ed. New York: John Wiley \& Sons, Inc, 2000.

7 Eagar K, Innes K. Creating a common language: the production and use of patient data in Australia. Commonwealth Department of Health, Housing, Local Government and Community Services. Canberra: AGPS, 1992.

8 Bradley LJ, Kirker SG, Corteen E, et al. Inappropriate acute neurosurgical bed occupancy and short falls in rehabilitation: implications for the National Service Framework. Br J Neurosurg 2006; 20: 36-39.

9 Poulos CJ, Gazibarich BM, Eagar K. Supporting work practices, improving patient flow and monitoring performance using a clinical information management system. Aust Health Rev 2007; 31: S79-S85.

10 Simmonds F, Stevermuer T. The AROC annual report: the state of rehabilitation in Australia in 2006. Aust Health Rev 2008; 32: 85-110.

11 Giles LC, Halbert J, Gray LC, et al. The distribution of health services for older people in Australia: where does transition care fit? Aust Health Rev 2009; 33: 572-582. 